\section{(A) Check for updates}

Cite this: Dalton Trans., 2022, 51 5034

Received 14th February 2022 Accepted 8th March 2022

DOI: $10.1039 / d 2 d t 00453 d$

rsc.li/dalton

\title{
Hydrogen-bonded cobalt(II)-organic framework: normal and reverse spin-crossover behaviours $\dagger$
}

\author{
Takuya Kanetomo, (D) * Zhen Ni and Masaya Enomoto \\ A novel hydrogen-bonded metal-organic framework (H-MOF) $\left[\mathrm{Co}(\mathrm{HL})_{2}\right](\mathrm{DMF})_{1.2}\left(\mathrm{H}_{2} \mathrm{O}\right)_{2.4}$ (1.solv), in which \\ $L=2,2^{\prime}: 6^{\prime}, 2^{\prime \prime}$-terpyridine-5,5"-diyl biscarboxylate, was prepared. An intermolecular single $\mathrm{H}$-bond \\ between carboxy and carboxylate sites was present in this compound. The crystal structure of 1.solv \\ showed a 4-fold interpenetrating $\mathrm{H}$-bonded diamond framework. After the desorption of the crystal sol- \\ vents, 1.desolv exhibited normal and reverse spin-crossover (SCO) behaviours, providing an asymmetric \\ thermal hysteresis loop.
}

\section{Introduction}

Hydrogen-bonded metal-organic frameworks (H-MOFs) have a metal complex as a building unit, in which they are connected through H-bonding. ${ }^{1-11}$ They have been applied in molecular porous materials like the typical $\mathrm{MOFs}^{12-14}$ and covalent organic frameworks (COFs). ${ }^{15,16}$ The magnitude of H-bonding determines the flexibility between units and can be controlled via the electrostatic interactions between the donor and acceptor moieties. Recently, organic/inorganic compounds undergoing self-assembly through $\mathrm{H}$-bonds have been intensively investigated in terms of their porosity, where these materials are referred to as hydrogen-bonded organic/inorganic frameworks (HOFs/HIFs). ${ }^{17-22}$ However, the strategic molecular construction of these systems depending on intermolecular interactions remains challenging. In particular, H-MOFs require the coexistence of coordination and hydrogen bonds.

$2,2^{\prime}: 6^{\prime}, 2^{\prime \prime}$-Terpyridine (tpy) is a three $\mathrm{N}$-donor ligand that can be chemically modified, ${ }^{23,24}$ and it, therefore, has been applied to the formation of supermolecules ${ }^{25}$ and coordination polymers. ${ }^{26,27}$ In tpy-metal complexes, those involving a $\mathrm{Co}^{2+}$ ion often exhibit unique magnetic properties such as the spin crossover (SCO) phenomenon, ${ }^{28-33}$ which is a reversible spin transition based on changes in the electron configuration due to external stimuli. ${ }^{34}$ The $\mathrm{Co}^{2+}$ centre exhibits high-spin (HS; $S=3 / 2$ ) and low-spin (LS; $S=1 / 2$ ) states, and the difference in the spin entropy is small. Cobalt(II)-SCO compounds can exhibit a sensitive response toward the absorption/desorp-

Department of Chemistry, Faculty of Science Division 1, Tokyo University of Science, 1-3 Kagurazaka, Shinjuku-ku, Tokyo 162-8603, Japan.

E-mail: kanetomo@rs.tus.ac.jp

$\dagger$ Electronic supplementary information (ESI) available. CCDC 2143196. For ESI and crystallographic data in CIF or other electronic format see DOI: 10.1039/ d2dt00453d tion of guest molecules. ${ }^{35-40}$ SCO-active Co-tpy complexes may act as switching components that are compatible with porous architectures such that functional materials may be developed.

A novel tpy-based ligand 2,2':6',2"-terpyridine-5,5"-diyl biscarboxylic acid $\left(\mathrm{H}_{2} \mathrm{~L}\right)$ as shown in Scheme 1 not only possesses the tpy moiety and contributes to the SCO behaviour, but it also contains two carboxy groups for intermolecular H-bonding. Carboxy groups have often been employed in H-bonded architectures. ${ }^{17,18}$ Here, two $\mathrm{H}_{2} \mathrm{~L}$ ligands are coordinated to one $\mathrm{Co}^{2+}$ centre, and the molecular structure exhibits a cruciform-like structure, providing two- or three-dimensional frameworks through the $\mathrm{H}$-bonds at the four carboxy sites. In this study, we prepared a novel cobalt(II) complex [Co $\left.(\mathrm{HL})_{2}\right](\mathrm{DMF})_{1.2}\left(\mathrm{H}_{2} \mathrm{O}\right)_{2.4}(\mathbf{1} \cdot \mathrm{solv})$, in which HL has carboxy and carboxyl sites as shown in Scheme 1. Crystallographic studies showed that an intermolecular $\mathrm{H}$-bond was present between the carboxy and carboxylate sites, thereby forming the H-bonded 3-D framework. There were crystal solvents in the void space, and they can be removed above $300 \mathrm{~K}$. The 1.desolv exhibited normal and reverse SCO behaviours with an asymmetric thermal hysteresis loop.

\section{Results and discussion}

Synthesis and characterization

We prepared $\mathrm{H}_{2} \mathrm{~L}$ using the 5,5"-dimethyl-2,2':6',2"terpyridine ${ }^{41,42}$ via oxidation with $\mathrm{KMnO}_{4}$. After complexation

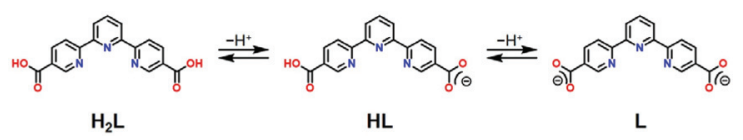

Scheme $1 \mathrm{H}_{2} \mathrm{~L}$ and its derivatives. 
between $\mathrm{H}_{2} \mathrm{~L}$ and $\mathrm{CoCl}_{2}$ in $\mathrm{N}, \mathrm{N}$-dimethylformamide (DMF) and $\mathrm{H}_{2} \mathrm{O}$, the product was purified by recrystallization through the vapour diffusion approach using the above mixture and 1,4dioxane, affording black block crystals in the form of $\left[\mathrm{Co}(\mathrm{HL})_{2}\right]$ $(\mathrm{DMF})_{1.2}\left(\mathrm{H}_{2} \mathrm{O}\right)_{2.4}(\mathbf{1} \cdot \mathrm{solv})$. The $\mathrm{HL}$ anion could be prepared during the above complexation process. For elemental analysis, the experimental values agreed with the calculated values, including 1.2 DMF and 2.4 $\mathrm{H}_{2} \mathrm{O}$ molecules after collection and immediate measurement. The presence of these solvents was also confirmed by thermal and X-ray crystallographic analysis (for details, see below).

\section{Single-crystal X-ray crystallography}

The crystal structure of $\mathbf{1} \cdot$ solv was evaluated at $93 \mathrm{~K}$, and it crystallized in a tetragonal $\mathrm{P4}_{2} / n$ space group, as shown in Table 1. In Fig. 1, the $\mathrm{Co}^{2+}$ centre is shown to be 6-coordinated with two tpy moieties, providing the $\mathrm{N}_{6}$ environment. The Co1-N1, Co1-N2, and Co1-N3 bond lengths were 2.1326(11), 2.0327(10), and 2.1313(11) A, respectively. The mean of the Co$\mathrm{N}$ lengths $\left(d_{\text {mean }}\right)$ was $2.099 \AA$. In addition, the octahedral distortion parameter $(\Sigma)^{43}$ was estimated to be $119.53^{\circ}$. These geometric parameters result in a suppressed octahedron environment along the N2, Co1, and N2* atoms. The $d_{\text {mean }}$ and $\Sigma$ parameters have been used to predict the spin state of the $\mathrm{Co}^{2+}$ centre. The relationship between these parameters was described in our previous work, ${ }^{40}$ and the relationship observed in this study indicates the HS state of the $\mathrm{Co}^{2+}$ centre.

The structural investigations of this system indicated the production of the $\mathrm{HL}$ anion. We next identified the four $\mathrm{C}-\mathrm{O}$ bond lengths in 1·solv. The C16-O1, C16-O2, C17-O3, and C17-O4 bond lengths were 1.2127(19), 1.292(2), 1.2661(19), and 1.2311(19) $\AA$, respectively. The typical $\mathrm{C}-\mathrm{O}$ and $\mathrm{C}-\mathrm{OH}$ bond lengths of the carboxy group are 1.226(20) and 1.305(20) $\AA$, whereas the typical $\mathrm{C}-\mathrm{O}$ bond length of the carboxylate group is $1.255(10) \AA .{ }^{44}$ These findings allow the C16, O1, and $\mathrm{O} 2$ and the $\mathrm{C} 17, \mathrm{O} 3$, and $\mathrm{O} 4$ moieties to be assigned to the carboxy and the carboxylate groups, respectively.

As shown in Fig. 2a, the nearest $\mathrm{O} 2 \cdots \mathrm{O} 3$ distance of 2.4782(13) A was smaller than the sum of the van der Waals

Table 1 Selected crystallographic data for 1.solv

\begin{tabular}{ll}
\hline Formula & $\mathrm{C}_{34} \mathrm{H}_{20} \mathrm{CoN}_{6} \mathrm{O}_{8}$ \\
FW & 699.49 \\
$T / \mathrm{K}$ & 93 \\
Crystal system & Tetragonal \\
Space group & $P 42 / n$ \\
$a / \AA$ & $14.3814(2)$ \\
$c / \AA$ & $18.3531(4)$ \\
$V / \AA^{3}$ & $3795.87(13)$ \\
$Z$ & 4 \\
$d_{\text {calcd }} / \mathrm{g} \mathrm{cm}^{-3}$ & 1.224 \\
$\mu(\mathrm{Mo} \mathrm{K \alpha}) / \mathrm{mm}^{-1}$ & 0.505 \\
$R(F)^{a}(I>2 \sigma(I))$ & 0.0311 \\
$R_{\mathrm{w}}\left(F^{2}\right)^{b}($ all data $)$ & 0.0807 \\
Goodness of fit & 1.050 \\
No. unique reflns & 4512 \\
${ }^{a} R=\sum|| F_{\mathrm{o}}|-| F_{\mathrm{c}}|| / \sum\left|F_{\mathrm{o}}\right| \cdot{ }^{b} R_{\mathrm{W}}=\left[\sum \mathrm{w}\left(\left|F_{\mathrm{o}}\right|-\left|F_{\mathrm{c}}\right|\right)^{2} / \sum \mathrm{w}\left|F_{\mathrm{o}}\right|^{2}\right]^{1 / 2}$.
\end{tabular}

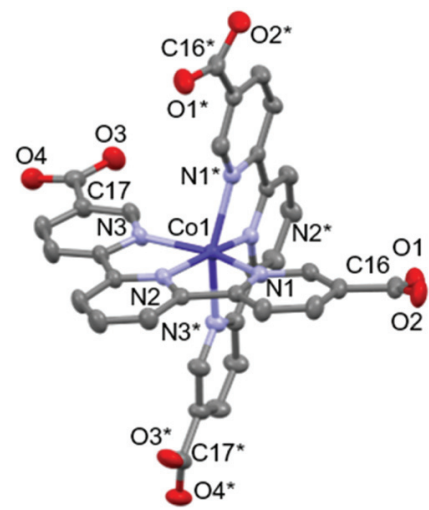

Fig. 1 Molecular structure of 1.solv. The $\mathrm{H}$ atoms are omitted for clarity. The thermal ellipsoids for non-hydrogen atoms are drawn at a $50 \%$ probability. Symmetric code: ${ }^{*}=3 / 2-x, 3 / 2-y, z$. a)

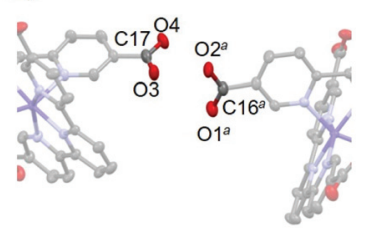

c)

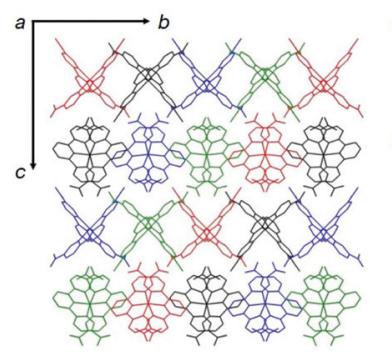

b)

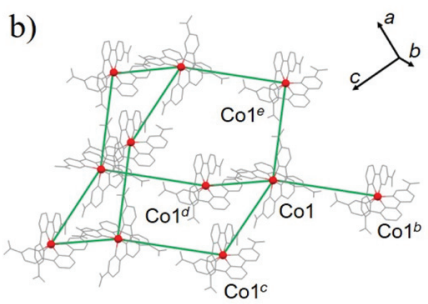

d)

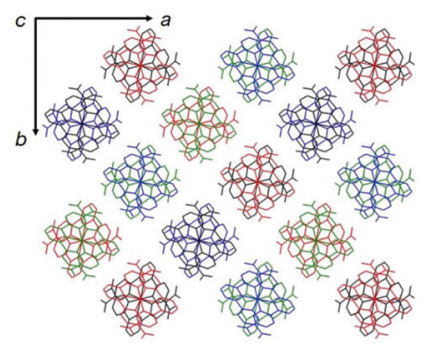

Fig. 2 (a) Intermolecular $\mathrm{H}$-bonding between carboxylate and carboxy sites. Symmetric code: $a=-1 / 2+y, 2-x,-1 / 2+z$. (b) H-bonding network. The red and grey colours represent $\mathrm{Co}$ and non-metal atoms, respectively. The green lines represent the connection of the Co centres via $\mathrm{H}$-bonding. Symmetric code: $b=1-y, 1 / 2+x,-1 / 2+z$. $c=1-y$, $-1 / 2+x, 1 / 2+z \cdot d=2-y, 1 / 2+x, 1 / 2+z . e=2-y,-1 / 2+x,-1 / 2+z$. The $\mathrm{H}$ atoms are omitted for clarity. Packing structures of 1 solv along the (c) a- and (d) c-axes. The red, green, blue and black colours represent the independent $\mathrm{H}$-bonding networks.

radii (O/O: $3.04 \AA),{ }^{45}$ indicating a strong single $\left\{\mathrm{O}-\mathrm{H} \cdots \mathrm{O}^{-}\right\}$-type $\mathrm{H}$-bond. Considering the symmetry of this structure, the [Co $(\mathrm{HL})_{2}$ ] unit extends in four directions, exhibiting a diamond framework (Fig. 2b). In addition, a 4-fold interpenetrating structure was present, as shown in Fig. 2c and d. The packing exhibited two species of 1-D pores along the [110] and [110] directions (Fig. 3). The space was occupied by the disordered crystal solvents, which were accounted for in the SQUEEZE/ PLATON program. From the calculations, the solvent-accessible void volume was estimated to be $27.9 \%$ per unit cell. An electron count of 78 electrons per formula unit was obtained, 
a)

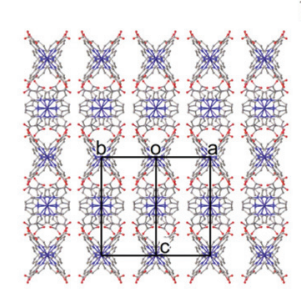

c)

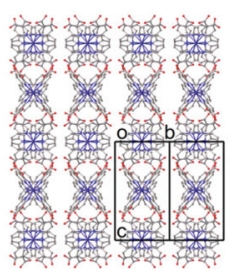

b)

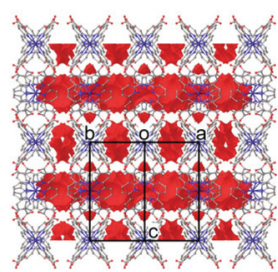

d)

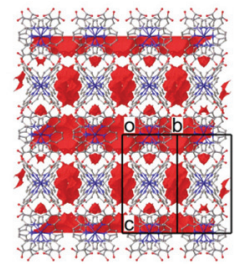

Fig. 3 Packing structure of 1.solv along the [110] (a and b) and [11̄0] (c and d) directions. (a) The only packing structure. (b) The packing structure with the solvent accessible void space (resolution, $0.1 \AA^{-1}$; a red surface). The $\mathrm{H}$ atoms are omitted for clarity.

which was close to the sum of the 1.2 DMF (48 electrons) and $2.4 \mathrm{H}_{2} \mathrm{O}$ (24 electrons) solvents. This finding is consistent with the elemental analysis results.

\section{Thermal analyses}

Compound $\mathbf{1} \cdot$ solv was evaluated via thermogravimetry (TG) and differential thermal analysis (DTA) techniques, as shown in Fig. 4. The TG curve exhibited three-step decreasing processes at 320,380 , and $420 \mathrm{~K}$. The weight loss $(\Delta w)$ for these processes were approximately $-3.3 \%,-7.0 \%$, and $-4.8 \%$, respectively. These findings indicate the desorption of the crystal solvents. Upon further heating, the TG curve exhibited a plateau at 440 to $560 \mathrm{~K}$. This plateau implies that $1 \cdot$ solv was fully desolvated (1.desolv, fw: 699.49). The $\Delta w$ of approximately $15.1 \%$ at 300 to $440 \mathrm{~K}$ is equivalent to fw 124.4 , corresponding to the sum of the 1.2 DMF (fw 87.7) and $2.4 \mathrm{H}_{2} \mathrm{O}$ (fw 43.2) solvents observed in the results of the elemental and crystallographic analyses.

\section{Powder X-ray crystallography}

Variable-temperature powder X-ray diffraction (VT-PXRD) was applied to 1·solv (Fig. 5). The simulation pattern from the

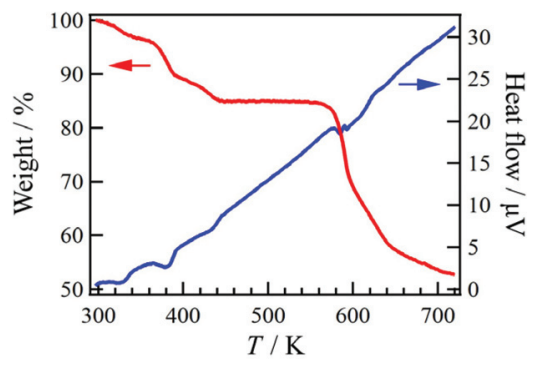

Fig. 4 TG (red) and DTA (blue) results for 1.solv in the temperature range $300-720 \mathrm{~K}$.

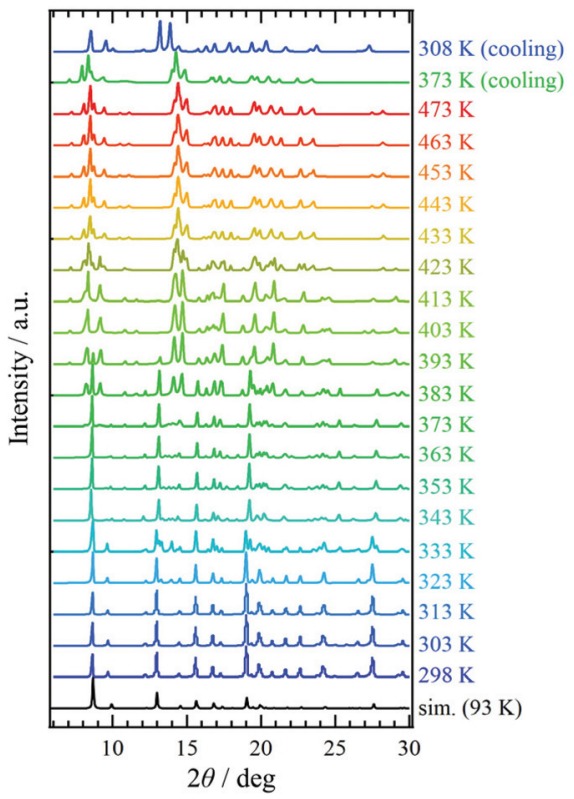

Fig. 5 Variable-temperature PXRD measurements of 1.solv from 298 to $473 \mathrm{~K}$ and from 473 to $308 \mathrm{~K}$. The simulation results (black line) were derived from the single-crystal $\mathrm{X}$-ray crystallographic results obtained at $93 \mathrm{~K}$.

above single-crystal XRD analysis was superposed onto Fig. 5 (indicated by the black line). The PXRD pattern at $298 \mathrm{~K}$ agrees well with the simulation results. Upon heating, the PXRD patterns changed three times at 333, 383, and $423 \mathrm{~K}$. These temperatures agreed with those associated with the desorption of the crystal solvents, and the spectra above $423 \mathrm{~K}$ represent the PXRD pattern for 1.desolv. Interestingly, the structural change that occurred around $383 \mathrm{~K}$ showed a significant difference in the PXRD patterns, and the change of spectra indicates the reduced symmetry of crystal structure compared with that of 1.solv.

On cooling from $473 \mathrm{~K}$, the PXRD pattern showed no change until $373 \mathrm{~K}$. The spectrum at $308 \mathrm{~K}$, however, changed and was close to that at $403 \mathrm{~K}$ in the heating process with the shift of peaks, implying the irreversible structural change owing to the desorption of crystal solvents. In addition, the finding indicates that 1.desolv captured the guest molecules, in which the water molecule is a good candidate, from the ambient environment in the cooling process from $373 \mathrm{~K}$.

\section{Magnetic properties}

The temperature dependence of $\chi_{\mathrm{m}} T$ for $1 \cdot \mathrm{solv}$ was measured at $0.5 \mathrm{~T}$ in the range of 10 to $350 \mathrm{~K}$, as shown in Fig. 6. The $\chi_{\mathrm{m}} T$ value of $1 \cdot$ solv was $2.37 \mathrm{~cm}^{3} \mathrm{~K} \mathrm{~mol}^{-1}$ at $300 \mathrm{~K}$, which is close to the expected value of $2.37 \mathrm{~cm}^{3} \mathrm{~K} \mathrm{~mol}^{-1}$ derived from the HS-cobalt(II) centre with $g=2.25$. Upon cooling, the $\chi_{\mathrm{m}} T$ value gradually decreased. This behaviour implies an intermolecular antiferromagnetic (AF) interaction or zero-field splitting (zfs) for the $\mathrm{Co}^{2+}$ centre. Conversely, when this system was heated from $320 \mathrm{~K}, \chi_{\mathrm{m}} T$ exhibited a sharply decreasing behav- 


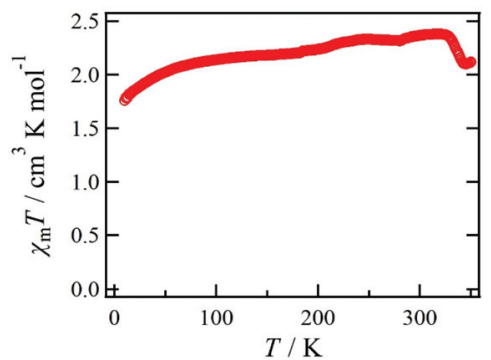

Fig. 6 Temperature dependence of the product $\chi_{\mathrm{m}} T$ measured at $0.5 \mathrm{~T}$ for 1.solv.

iour, indicating a structural change triggered by the desorption of crystal solvents.

The $\chi_{\mathrm{m}} T v s . T$ plots for 1.desolv upon heating, cooling, and 2nd heating processes from 10 to $400 \mathrm{~K}$ are shown in Fig. 7 . The sample 1.desolv used for these measurements was used after undergoing the above PXRD measurements. The $\chi_{\mathrm{m}} T$ values above $350 \mathrm{~K}$ and below $250 \mathrm{~K}$ showed almost the same behaviour in all processes. The $\chi_{\mathrm{m}} T$ values obtained at 400 and $200 \mathrm{~K}$ during the 1 st heating process were 2.43 and $1.40 \mathrm{~cm}^{3} \mathrm{~K}$ $\mathrm{mol}^{-1}$, respectively. The former is close to $2.42 \mathrm{~cm}^{3} \mathrm{~K} \mathrm{~mol}^{-1}$ derived from the HS-cobalt(II) centre with $g=2.27$, whereas the latter agrees well with $1.45 \mathrm{~cm}^{3} \mathrm{~K} \mathrm{~mol}^{-1}$ derived from the $\mathrm{HS} / \mathrm{LS}$ state of $1 / 1$, in which the expected value of the LS-cobalt(II) centre with $g=2.27$ is $0.483 \mathrm{~cm}^{3} \mathrm{~K} \mathrm{~mol}^{-1}$. These $\chi_{\mathrm{m}} T$ values indicate that 1.desolv exhibited an incomplete SCO behaviour in the range of 200 to $400 \mathrm{~K}$. Conversely, the $\chi_{\mathrm{m}} T$ values obtained during the cooling process traced the outside of those obtained during heating; therefore, a thermal hysteresis loop occurred. Below $250 \mathrm{~K}, \chi_{\mathrm{m}} T$ gradually decreased and reached $0.92 \mathrm{~cm}^{3} \mathrm{~K} \mathrm{~mol}^{-1}$ at $10 \mathrm{~K}$. This finding may have resulted from the intermolecular $\mathrm{AF}$ interaction or the zfs of the Co centre.

Although 1.desolv exhibited typical SCO behaviour during the cooling process, a decrease of $\chi_{\mathrm{m}} T$ was observed from 250 to $270 \mathrm{~K}$ during the 1 st and 2 nd heating processes, as shown in the inset of Fig. 7. Note that a peak can be observed around

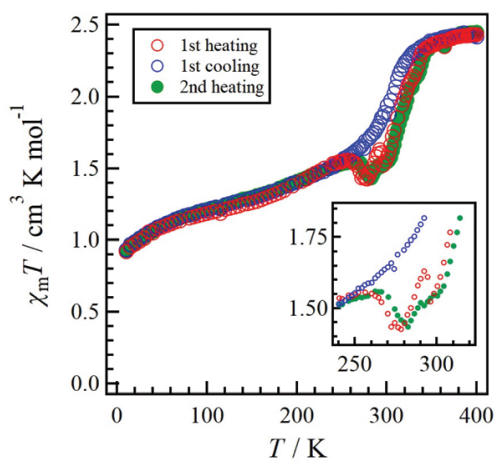

Fig. 7 Temperature dependence of the product $\chi_{\mathrm{m}} T$ measured at $0.5 \mathrm{~T}$ for 1.desolv. The red, blue, and green colours represent the 1st heating, 1 st cooling, and 2 nd heating processes, respectively. The inset shows an enlarged view of the 240 to $320 \mathrm{~K}$ region.
$290 \mathrm{~K}$ in the 1st heating process, which nearly vanished in the 2nd heating process, implying the desorption of the reabsorbed guest molecules. To understand the atypical SCO behaviour that was observed during the heating process, we propose the mechanism shown in Scheme 2. The $\chi_{\mathrm{m}} T$ behaviour from 400 to $200 \mathrm{~K}$ exhibitions a spin transition between the HS and 1/1 HS/LS states. The spin state at $200 \mathrm{~K}$ indicates the presence of two non-equivalent $\mathrm{Co}^{2+}$ ions, although 1.solv showed only one crystallographic independent $\mathrm{Co}^{2+}$ ion. To illustrate this spin state, it may be reasonable to assume that at least two crystallographic independent systems arise from the 4-fold interpenetrating diamond frameworks owing to the structural change resulting from the desorption of solvents. Therefore, the SCO behaviour in half of the frameworks upon cooling is as shown in Scheme 2. The spin alignment at $200 \mathrm{~K}$ should be alternating for the HS and LS states to achieve an even chemical pressure from the HS frameworks.

Upon heating from $200 \mathrm{~K}$, the $\chi_{\mathrm{m}} T$ value increased owing to the SCO behaviour, and it then decreased from $255 \mathrm{~K}$ and returned to the $1 / 1 \mathrm{HS} / \mathrm{LS}$ state at $280 \mathrm{~K}$. These findings indicate a reverse $\mathrm{SCO}$ ( $\mathrm{rSCO}$ ) phenomenon, which is the spin transition from the HS to LS states. Owing to the reverse and normal SCO behaviour, 1 exhibits the steady-state conditions between the HS and LS groups, as shown in Scheme 2. These conditions were broken upon further heating, and all $\mathrm{Co}^{2+}$ centres showed the HS state.

The rSCO behaviour has been reported in the iron(II) ${ }^{46-49}$ and cobalt(II) complexes, ${ }^{33,37,50-53}$ and it is mainly explained as originating in the structural phase transition such as an order-disorder transition. For the rSCO behaviour of 1.desolv, we have focused on the intermolecular H-bond between carboxy and carboxylate sites. From the crystallographic studies of $\mathbf{1} \cdot$ solv, there was the intermolecular single $\{\mathrm{O}-$ $\left.\mathrm{H} \cdots \mathrm{O}^{-}\right\}$-typed $\mathrm{H}$-bond, which has double-well energy potential. When the distance between carboxy and carboxylate sites is shortened, the $\mathrm{H}$-bond can exhibit the $\{\mathrm{O} \cdots \mathrm{H} \cdots \mathrm{O}\}^{-}$form having the single-well potential. ${ }^{54}$ It is known to demonstrate the crossover between the above two-typed $\mathrm{H}$-bonds depending on the temperature, and the crossover gives the structural phase transition. ${ }^{55-58}$ Therefore, we have concluded the $\mathrm{rSCO}$ observed in 1.desolv may be triggered by the structural phase transition corresponding to the above crossover of $\mathrm{H}$-bonds.

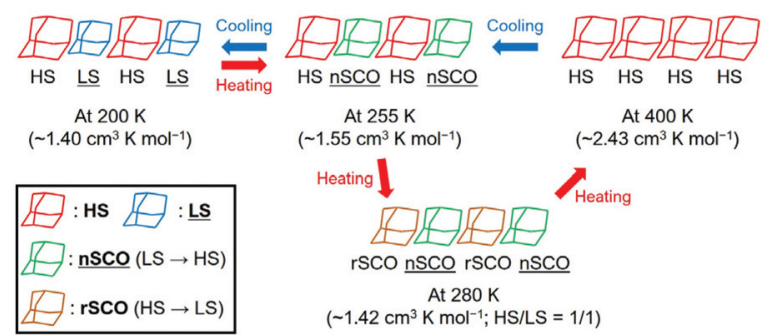

Scheme 2 Proposed mechanism of the asymmetric SCO behaviour for 1.desolv in the temperature range 200-400 K. The normal and reverse $\mathrm{SCO}$ behaviours represent $\mathrm{nSCO}$ and $\mathrm{rSCO}$, respectively. 


\section{Conclusions}

In summary, we prepared a novel H-MOF 1.solv formed by cobalt(II)-SCO units. Compound 1-solv exhibited a H-bonded diamond framework and a 4-fold interpenetrating structure with 1-D pores. The crystal solvents were occupied in the void spaces, and the desorption of those solvents caused three structural changes. Compound 1.desolv exhibited normal and reverse SCO behaviours with asymmetric thermal hysteresis. H-MOF 1-desolv exhibited a porous architecture and magnetic switching characteristics. For improvement of the reversibility and selectivity of guest molecules in this system, a multi-component H-MOF system is a good candidate; for example, a twocomponent $\mathrm{H}-\mathrm{MOF}$, which is a cocrystal of the $\left[\mathrm{Co}(\mathrm{HL})_{2}\right]$ unit and an $\mathrm{H}$-bonding formable linker. The multi-component H-MOF system presented in this study may be used to form a variety of porous structures.

\section{Experimental}

\section{Materials and methods}

$5,5^{\prime \prime}$-Dimethyl-2,2':6',2"-terpyridine was prepared by the reported procedure. ${ }^{41,42}$ Anhydrous $N, N$-dimethylformamide (DMF) was purchased from KANTO Chemical Co., Inc. and used without further purification. ${ }^{1} \mathrm{H}$ and ${ }^{13} \mathrm{C}$ NMR experiments (400 and $100 \mathrm{MHz}$, respectively) were performed on JNM-ECZ400S (JEOL). The chemical shift (given in ppm) was measured versus a reference peak of tetramethylsilane (TMS). The splitting patterns are designated as follows: s (singlet), d (doublet), t (triplet), and dd (doublet of doublets). Elemental analyses were carried out with a PerkinElmer Series II CHNS/O 2400 analyzer. Melting point measurement was performed on ATM-02 (AS ONE). High-resolution mass spectra (HRMS) were recorded in electrospray ionization (ESI) mode using an AccuTOF-JMS-T100LP (JEOL) spectrometer. The specimen was dissolved in a small amount of DMF, and then the solution was diluted with methanol. Infrared (IR) spectra were obtained on an FT/IR-4600 (JASCO) spectrometer using a diamond attenuated total reflectance (ATR) method. The spectral data are obtained as major peaks in wavenumbers $\left(\mathrm{cm}^{-1}\right)$ are recorded in a spectral window of 4000-400 $\mathrm{cm}^{-1}$. Electronic spectra (ultraviolet-visible, UV-Vis) were obtained on a JASCO V-650 spectrometer. Thermogravimetry (TG) and differential thermal analysis (DTA) of $\mathbf{1} \cdot$ solv were carried out on a Bruker AXS TG2010SA instrument. The temperature scan rate was $5 \mathrm{~K}$ $\min ^{-1}$ in the range of $300-720 \mathrm{~K}$. Powder X-ray diffraction (PXRD) spectra were recorded using a Rigaku MiniFlex600 diffractometer ( $\mathrm{Cu}$ K $\alpha$ radiation: $\lambda=1.541862 \AA)$ in the range of 298-473 K.

\section{Synthesis of $2,2^{\prime}: 6^{\prime}, 2^{\prime \prime}$-terpyridine-5,5"-diyl biscarboxylic acid} $\left(\mathbf{H}_{2} \mathbf{L}\right)$

5,5"-Dimethyl-2,2':6',2"-terpyridine (720.0 mg, $2.76 \mathrm{mmol}$ ) was dissolved in $4 / 3$ pyridine $/ \mathrm{H}_{2} \mathrm{O}(70 \mathrm{~mL})$, and thus $\mathrm{KMnO}_{4}$ (4.06 g, $25.7 \mathrm{mmol}$ ) was added to the solution. After the mixture was refluxed for $4 \mathrm{~h}, \mathrm{KMnO}_{4}(2.02 \mathrm{~g}, 12.8 \mathrm{mmol})$ was added, again. The mixture was refluxed for $12 \mathrm{~h}$ and quenched by ethanol. The filtrate was concentrated under reduced pressure. The crude was dissolved in a small amount of $\mathrm{H}_{2} \mathrm{O}$, and the solution was made $\mathrm{pH} 3$ by a dilute $\mathrm{HCl}$ aqueous, affording colorless precipitants. The obtained colorless powder $\mathrm{H}_{2} \mathrm{~L}$ was a yield of $719.8 \mathrm{mg}$ (2.24 mol, 81\%). Mp. $>200{ }^{\circ} \mathrm{C}$. ${ }^{1} \mathrm{H}$ NMR (400 MHz, DMSO- $d_{6}$, Fig. S1 $\dagger$ ): $\delta 13.57$ (br s, $2 \mathrm{H}), 9.21(\mathrm{~s}, 2 \mathrm{H}), 8.77$ (d, $J=8.2 \mathrm{~Hz}, 2 \mathrm{H}), 8.57$ (d, $J=7.7 \mathrm{~Hz}$, $2 \mathrm{H}), 8.48\left(\mathrm{dd}, J=8.2, J^{\prime}=1.6 \mathrm{~Hz}, 2 \mathrm{H}\right)$, and $8.20(\mathrm{t}, J=7.7 \mathrm{~Hz}$, $1 \mathrm{H}) .{ }^{13} \mathrm{C}$ NMR (100 MHz, DMSO- $d_{6}$, Fig. S2 $\dagger$ ): $\delta$ 166.13, 158.00, 154.02, 150.20, 138.98, 138.35, 126.78, 122.28, and 120.54. HRMS (ESI ${ }^{+}$, Fig. S3 $\dagger$ ): $m / z$ calcd for $\mathrm{C}_{17} \mathrm{H}_{12} \mathrm{~N}_{3} \mathrm{O}_{4}[\mathrm{M}+\mathrm{H}]^{+}$: 322.08278, found 322.08251. IR (ATR): 2841, 1682, 1591, 1557, 1421, 1380, 1298, 1138, 1020, 921, 824, 722, 649, and $541 \mathrm{~cm}^{-1}$. UV-vis (DMF) $\lambda_{\max } / \mathrm{nm}(\log \varepsilon) 294$ (1.06).

\section{Synthesis of $\left[\mathrm{Co}(\mathrm{HL})_{2}\right](\mathrm{DMF})_{1.2}\left(\mathrm{H}_{2} \mathrm{O}\right)_{2.4}(1 \cdot \operatorname{solv})$}

The $\mathrm{H}_{2} \mathrm{~L}$ (81.73 mg, $0.262 \mathrm{mmol}$ ) and $\mathrm{CoCl}_{2}(14.12 \mathrm{mg}$, $0.109 \mathrm{mmol})$ were dissolved in DMF $(10 \mathrm{~mL})$ and $\mathrm{H}_{2} \mathrm{O}(3 \mathrm{~mL})$, respectively. The above two solutions were mixed and stirred for 15 minutes at $0{ }^{\circ} \mathrm{C}$. The red mixture was crystallized under 1,4-dioxane vapor diffusion for 5 days. The black block crystals were collected, and the yield was $53.05 \mathrm{mg}$ (0.0674 mmol, $62 \%$ ). Mp. $272{ }^{\circ} \mathrm{C} \quad$ (decomp.). Anal. Calc. for $\mathrm{C}_{37.6} \mathrm{H}_{33.2} \mathrm{CoN}_{7.2} \mathrm{O}_{11.6}\left(1 \cdot(\mathrm{DMF})_{1.2}\left(\mathrm{H}_{2} \mathrm{O}\right)_{2.4}\right): \mathrm{C}, 54.38 ; \mathrm{H}, 4.03 ; \mathrm{N}$, 12.14\%. Found: C, 54.38; H, 3.84; N, 12.00\%. IR (ATR): 3069, $1600,1449,1354,1249,1132,1025,770$, and $718 \mathrm{~cm}^{-1}$.

\section{Single-crystal X-ray diffraction}

The X-ray diffraction data of $\mathbf{1 \cdot s o l v}$ at $93 \mathrm{~K}$ were collected on a Rigaku VariMax Dual (Mo K $\alpha$ radiation: $\lambda=0.71073 \AA$ ). The selected crystallographic data are given in Table 1 . X-ray data analyses were carried out using the SHELXT $^{59}$ and SHELXL ${ }^{60}$ programs operated with the Olex 2 interface. ${ }^{61}$ All the hydrogen atoms were refined as "riding". The thermal displacement parameters of the non-hydrogen atoms were refined anisotropically. The contribution of the disordered solvent was removed using the SQUEEZE option from PLATON operated with the Olex2 interface. ${ }^{61}$ The estimated total solvent-accessible void space (1.2 $\AA$ probe) was $1060.9 \AA^{3}$ per the unit cell $(27.9 \%)$ and 78 electrons per unit cell. The squeeze electron count correlates with the electron density of 1.2 DMF and 2.4 $\mathrm{H}_{2} \mathrm{O}$ molecules of unit cell (72 electrons). Fig. 3 represents the packing structure along with the [110] and [110] directions, respectively. Each figure also shows the solvent-accessible void space (a red surface). The CCDC number is 2143196. $\dagger$

\section{Magnetic measurements}

The direct current magnetic susceptibilities of 1·solv and 1.desolv were measured on a Quantum Design MPMS-XL7AC SQUID magnetometer equipped with a $7 \mathrm{~T}$ coil under the static field of $0.5 \mathrm{~T}$. The sample 1.desolv was used after the PXRD measurement, in which the sample was heated to $473 \mathrm{~K}$. The 1.solv was measured on heating in the $10-350 \mathrm{~K}$ range shown in Fig. 6, whereas 1.desolv was measured on heating, 
cooling, and then 2 nd heating processes in the $10-400 \mathrm{~K}$ range shown in Fig. 7. The magnetic data were corrected using diamagnetic blank data of sample holder measured separately. The diamagnetic contribution of the sample itself was estimated from Pascal's constant. ${ }^{62}$

\section{Conflicts of interest}

There are no conflicts to declare.

\section{Acknowledgements}

This study was financially supported by KAKENHI (JSPS. 21K14604). The crystallography work for $\mathbf{1} \cdot$ solv was conducted at the Advanced Characterization Nanotechnology Platform of the University of Tokyo, supported by the "Nanotechnology Platform" of MEXT, Japan.

\section{Notes and references}

1 D. S. Reddy, S. Duncan and G. K. H. Shimizu, Angew. Chem., Int. Ed., 2003, 42, 1360.

2 C.-L. Chen and A. M. Beatty, J. Am. Chem. Soc., 2008, 130, 17222.

3 S. S. Mondal, A. Bhunia, A. Kelling, U. Schilde, C. Janiak and H.-J. Holdt, Chem. Commun., 2014, 50, 5441.

4 J. Wu, M. Guo, X.-L. Li, L. Zhao, Q.-F. Sun, R. A. Layfield and J. Tang, Chem. Commun., 2018, 54, 12097.

5 Z. Bao, D. Xie, G. Chang, H. Wu, L. Li, W. Zhou, H. Wang, Z. Zhang, H. Xing, Q. Yang, M. J. Zaworotko, Q. Ren and B. Chen, J. Am. Chem. Soc., 2018, 140, 4596.

6 G. Gerer, F. Melin, P. Hellwig, M. W. Hosseini and S. Ferlay, Inorg. Chem., 2019, 58, 1541.

7 H.-L. Wang, X.-F. ma, Z.-H. Zhu, Y.-Q. Zhang, H.-H. Zou and F.-P. Liang, Inorg. Chem. Front., 2019, 6, 2906.

8 Z.-Q. Shi, N.-N. Ji, K.-M. Guo and G. Li, Appl. Surf. Sci., 2020, 504, 144484.

9 Z.-H. Zhu, H.-L. Wang, H.-H. Zou and F.-P. Liang, Dalton Trans., 2020, 49, 10708.

10 B. Yuan, Y. Tang, G. Gou, W. Dan and L. Li, CrystEngComm, 2020, 22, 3921.

11 D. I. Konovalov, A. A. Ivanov, Y. A. Vorotnikov, N. V. Kuratieva, I. V. Eltsov, K. A. Kovalenko and M. A. Shestopalov, Inorg. Chem., 2021, 60, 14687.

12 H. Furukawa, K. E. Cordova, M. O'Keeffe and O. M. Yaghi, Science, 2013, 341, 1230444.

13 Z.-F. Wu, B. Tan, W. P. Lustig, E. Velasco, H. Wang, X.-Y. Huang and J. Li, Coord. Chem. Rev., 2019, 399, 213025.

14 L. S. Xie, G. Skorupskii and M. Dincă, Chem. Rev., 2020, 120, 8536.

15 X. Chen, K. Geng, R. Liu, K. T. Tan, Y. Gong, Z. Li, S. Tao, Q. Jiang and D. Jiang, Angew. Chem., Int. Ed., 2020, 59, 5050 .

16 H. L. Nguyen, Chem. Sci., 2021, 12, 8632.
17 I. Hisaki, C. Xin, K. Takahashi and T. Nakamura, Angew. Chem., Int. Ed., 2019, 58, 11160.

18 I. Hisaki, J. Inclusion Phenom. Macrocyclic Chem., 2020, 96, 215.

19 R. Liang, J. Samanta, B. Shao, M. Zhang, R. J. Staples, A. D. Chen, M. Tang, Y. Wu, I. Aprahamian and C. Ke, Angew. Chem., Int. Ed., 2021, 60, 23176.

20 J. Zhang, Y. Feng, R. J. Staples, J. Zhang and J. M. Shreeve, Nat. Commun., 2021, 12, 2146.

21 Y.-H. Luo, L. Zhang, W.-X. Fang, S.-H. Ma, H. Dong, S. Su, Z.-Y. Zheng, D.-N. Li and L.-H. Zhai, Chem. Commun., 2021, 57, 5901.

22 M. Igarashi, T. Nozawa, T. Matsumoto, F. Yagihashi, T. Kikuchi and K. Sato, Nat. Commun., 2021, 12, 7025.

23 A. M. W. C. Thompson, Coord. Chem. Rev., 1997, 160, 1.

24 A. Wild, A. Winter, F. Schlütter and U. S. Schubert, Chem. Soc. Rev., 2011, 40, 1459.

25 E. C. Constable, Chem. Soc. Rev., 2007, 36, 246.

26 P. R. Andres and U. S. Schubert, Adv. Mater., 2004, 16, 1043.

27 J. Veliks, J.-C. Tseng, K. I. Arias, F. Weissher, A. Linden and J. S. Siegel, Chem. Sci., 2014, 5, 4317.

28 S. Hayami, Y. Komatsu, T. Shimizu, H. Kamihata and Y. H. Lee, Coord. Chem. Rev., 2011, 255, 1981.

29 X. Zhang, H. Xie, M. Ballesteros-Rivas, Z.-X. Wang and K. R. Dunbar, J. Mater. Chem. C, 2015, 3, 9292.

30 Y. Guo, X.-L. Yang, R.-J. Wei, L.-S. Zheng and J. Tao, Inorg. Chem., 2015, 54, 7670.

31 A. Ondo and T. Ishida, Crystals, 2018, 8, 155.

32 Y. Pankratova, D. Aleshin, I. Nikovskiy, V. Novikov and Y. Nelyubina, Inorg. Chem., 2020, 59, 7700.

33 R. Akiyoshi, R. Ohtani, L. F. Lindoy and S. Hayami, Dalton Trans., 2021, 50, 5065.

34 Spin Crossover in Transition Metal Compounds I, II and III, ed. P. Gütlich and H. A. Goodwin, Springer, Berlin, Germany, 2004.

35 D. Shao, L. Shi, F.-X. Shen, X.-Q. Wei, O. Sato and X.-Y. Wang, Inorg. Chem., 2019, 58, 11589.

36 M. Nakaya, W. Kosaka, H. Miyasaka, Y. Komatsumaru, S. Kawaguchi, K. Sugimoto, Y. Zhang, M. Nakamura, L. F. Lindoy and S. Hayami, Angew. Chem., Int. Ed., 2020, 59, 10658.

37 F. Kobayashi, Y. Komatsumaru, R. Akiyoshi, M. Nakamura, Y. Zhang, L. F. Lindoy and S. Hayami, Inorg. Chem., 2020, 59, 16843.

38 H. Zenno, F. Kobayashi, M. Nakamura, Y. Sekine, L. F. Lindoy and S. Hayami, Dalton Trans., 2021, 50, 7843.

39 Y.-F. Deng, Y.-N. Wang, X.-H. Zhao and Y.-Z. Zhang, CCS Chem., 2021, 3, 3277.

40 T. Kanetomo, K. Inokuma, Y. Naoi and M. Enomoto, Dalton Trans., 2021, 50, 11243.

41 T. Seckin, I. Özdemir, S. Köytepe and N. Gürbüz, J. Inorg. Organomet. Polym., 2009, 19, 143.

42 B. Golesorkhi, L. Guénée, H. Nozary, A. Fürstenberg, Y. Suffren, S. V. Eliseeva, S. Petoud, A. Hauser and C. Piguet, Chem. - Eur. J., 2018, 24, 13158. 
43 C. A. Kilner and M. A. Halcrow, Dalton Trans., 2010, 39, 9008.

44 F. H. Allen, D. G. Watson, L. Brammer, A. G. Orpen and R. Taylor, in International Tables for Crystallography, ed E. Prince, Springer, Berlin, 2006, vol. C, pp. 790.

45 A. Bondi, J. Phys. Chem., 1964, 68, 441.

46 M. Seredyuk, M. C. Muñoz, M. Castro, T. Romero-Morcillo, A. B. Gaspar and J. A. Real, Chem. - Eur. J., 2013, 19, 6591.

47 M. Yamashita and T. Ishida, J. Mater. Chem. C, 2015, 3, 7784.

48 M. Weselski, M. Książek, P. Mess, J. Kusz and R. Bronisz, Chem. Commun., 2019, 55, 7033.

49 R. Kulmaczewski, F. Bamiduro, N. Shahid, O. Cespedes and M. A. Halcrow, Chem. - Eur. J., 2021, 27, 2082.

50 G. Agustí, C. Bartual, V. Martínez, F. J. Muñoz-Lara, A. B. Gaspar, M. C. Muñoz and J. A. Real, New J. Chem., 2009, 33, 1262.

51 S. Hayami, M. Nakaya, H. Ohmagari, A. S. Alao, M. Nakamura, R. Ohtani, R. Yamaguchi, T. Kuroda-Sowa and J. K. Clegg, Dalton Trans., 2015, 44, 9345.

52 K. Kuroiwa, T. Arie, S. Sakurai, S. Hayami and T. J. Deming, J. Mater. Chem. C, 2015, 3, 7779.
53 Z.-S. Yao, S.-Q. Wu, Y. Kitagawa, S.-Q. Su, Y.-G. Huang, G.-L. Li, Z.-H. Ni, H. Nojiri, Y. Shiota, K. Yoshizawa, S. Kang, S. Kanegawa and O. Sato, Angew. Chem., Int. Ed., 2017, 56, 717.

54 S. J. Grabowski, Annu. Rep. Prog. Chem., Sect. C: Phys. Chem., 2006, 102, 131.

55 E. J. Samuelsen and D. Semmingsen, J. Phys. Chem. Solids, 1977, 38, 1275.

56 T. Mitani, G. Saito and H. Urayama, Phys. Rev. Lett., 1988, 60, 2299.

57 A. Ueda, Bull. Chem. Soc. Jpn., 2017, 90, 1181.

58 C. Shi, X. Zhang, C.-H. Yu, Y.-F. Yao and W. Zhang, Nat. Commun., 2018, 9, 481.

59 G. M. Sheldrick, Acta Crystallogr., Sect. A: Found. Adv., 2015, $71,3$.

60 G. M. Sheldrick, Acta Crystallogr., Sect. C: Struct. Chem., 2015, 71, 3.

61 L. J. Bourhis, O. V. Dolomanov, R. J. Gildea, J. A. K. Howard and H. Puschmann, Acta Crystallogr., Sect. A: Found. Adv., 2015, 71, 59.

62 O. Kahn, Molecular Magnetism, VCH-Verlag, Weinheim, New York, 1993. 